\title{
Screening Potential Citrus Rootstocks for Phytophthora nicotianae Tolerance
}

\author{
Madhurababu Kunta and Sandy Chavez \\ Texas A\&M University-Kingsville Citrus Center, 312 N. International \\ Boulevard, Weslaco, TX 78599
}

\section{Zenaida Viloria}

UK Research and Education Center at Princeton, Entomology, 1205 Hopkinsville Street, Princeton, KY 42445

\section{Hilda S. del Rio}

Texas A\&M University-Kingsville Citrus Center, 312 N. International Boulevard, Weslaco, TX 78599

\section{Madhavi Devanaboina \\ The University of Texas Rio Grande Valley, School of Mathematics and Statistical Sciences, 1201 W. University Drive, Edinburg, TX 78539}

\section{George Yanev}

The University of Texas Rio Grande Valley, School of Mathematics and Statistical Sciences, 1201 W. University Drive, Edinburg, TX 78539; and Institute of Mathematics and Informatics, Bulgarian Academy of Sciences, 8 Acad. G. Bonchev Str., 1113 Sofia, Bulgaria

\section{Jong-Won Park and Eliezer S. Louzada}

Texas A\&M University-Kingsville Citrus Center, 312 N. International Boulevard, Weslaco, TX 78599

\section{Additional index words. citrus, Phytophthora, root rot, rootstock, tolerance}

\begin{abstract}
Seeds from four citrus rootstocks including sour orange, Bitters-C22 citrandarin, Sarawak pummelo $\times$ Rio Red grapefruit, and Sarawak pummelo $\times$ Bower mandarin were exposed to high inoculum levels of Phytophthora nicotianae to screen for tolerance. Inoculation of pregerminated seeds (PGIS) and non-PGIS was carried out. The average $P$. nicotianae propagule counts from the soil samples where these seedlings were raised ranged from 424 to 1361 colony forming units $/ \mathrm{cm}^{3}$. The proportion of live to dead plants was recorded at 11 months postinoculation, which showed that Sarawak $\times$ Bower performed significantly better than other rootstocks. Evaluation of the rootstocks 18 months postinoculation resulted in only one surviving sour orange plant, which suggests potential rootstock resistance.
\end{abstract}

Citrus trees are susceptible to a variety of diseases and can be combating more than one at the same time. In the Lower Rio Grande Valley (LRGV) of south Texas, a common oomycete causing major crop losses in citrus is Phytophthora nicotianae (Kunta et al., 2007). Two species of Phytophthora, P. nicotianae Breda de Haan (synonymous with $P$. parasitica Dast.) and $P$. citrophthora (Sm. $\&$ Sm.) Leonian are the most prevalent and highly destructive pathogens affecting citriculture worldwide (Graham and Menge,

Received for publication 6 Feb. 2020. Accepted for publication 22 Apr. 2020.

Published online 28 May 2020

This research was possible because of financial support from Texas Citrus Producers Board.

E.S.L. is the corresponding author. E-mail: eliezer. louzada@tamuk.edu.

This is an open access article distributed under the CC BY-NC-ND license (https://creativecommons. org/licenses/by-nc-nd/4.0/). stunting, premature defoliation and branch dieback (Naqvi, 2004). Foot rot infection begins above the soil surface where a lesion on the bark can extend from the scion to the base of the rootstock (Savita and Nagpal, 2012). Gum will exude from diseased bark, serving as a clear characteristic of $P$. nicotianae infection and is referred to as gummosis (Graham and Menge, 1999). Gumming is more noticeable during dry weather vs. wet seasons when rain may potentially rinse away obvious gumming evidence (Savita and Nagpal, 2012). Plants infected with $P$. nicotianae may have a decayed root system leaving roots sloughed of all outer layers. The production of new fibrous roots is apparently outpaced by root death in heavily infected mature trees (Graham, 1995). Root death will ultimately decline the overall health of the host plant as seen in tobacco, ornamental plants, tomato, and citrus cultivars (Lamour et al., 2003).

The economic losses for the citrus industry worldwide exclusively caused by $P$. nicotianae are difficult to estimate as most trees are often affected by more than one disease at the same time (Ludowici et al., 2013). In California, the largest citrus producer in the United States, brown rot and root rot caused by Phytophthora accounted for \$12.9 million annual loss (Savita and Nagpal, 2012). In Florida, the second top U.S. citrus producer, Phytophthora damage has been estimated to be $\approx \$ 30$ to $\$ 60$ million annual yield loss, without control treatments (Graham and Menge, 1999). In Texas, there are no reports on the impact of Phytophthora; however, because of the use of flood irrigation, Phytophthora is endemic.

Phytophthora nicotianae disease management strategies include use of resistant rootstocks, biological control, fungicides, clean material for propagation, and irrigation with adequate drainage (Cacciola and di San Lio, 2008). Metalaxyl and phosphite fungicides have been reported to be effective in combating Phytophthora diseases when applied at proper dosages and at right time frame (Graham and Feichtenberger, 2015). Phytopththora can be controlled with fungicides, but overuse may render them ineffective through resistance development (Timmer et al., 1998). Biological control efforts using Penicillium funiculosum and Chaetomium globosum on citrus cultivars (Fang and Tsao, 1995; Hung et al., 2015) have been proven effective; however, it is not preferred as a large-scale control strategy due to specific temperature, soil $\mathrm{pH}$, and host preference for different biological control agents.

Use of resistant rootstocks is an ideal and long-term solution to fight Phytophthora diseases. Sour orange is one of the few rootstock that can produce high yields and yet tolerate the high $\mathrm{pH}$ calcareous soils common in the LRGV, and therefore, it is the predominant rootstock planted in this area. Phytophthora infected trees with typical symptoms of foot rot, root rot, and gummosis are commonly present. Field trials with Phytophthora-infected rootstocks in Florida showed Swingle citrumelo and Carrizo citrange having high 
seedling mortality whereas sour orange did not have significant seedling mortality (Bowman et al., 2002, 2003). Graham (1990) tested seven rootstocks including trifoliate orange (Poncirus trifoliata), Ridge Pineapple sweet orange, Carrizo citrange, Swingle citrumelo, sour orange, Cleopatra mandarin, and Volkameriana lemon; the results revealed that trifoliate orange and Swingle citrumelo were among the most tolerant to root rot. Similarly, trifoliate orange and Swingle citrumelo performed better than the other rootstocks in their ability to regenerate roots under Phytophthora infection (Graham, 1995). In Florida, Carrizo citrange and Swingle citrumelo were considered tolerant and moderately resistant rootstocks, respectively (Graham and Feichtenberger, 2015); however, the same rootstocks failed to grow under field trials conducted in the LRGV (Louzada et al., 2008) due to soil characteristics.

There is an urgent need for a superior rootstock that can provide resistance to Phytophthora diseases, tolerate alkaline soil and the weather conditions in the LRGV area, and yet produce high quality fruit. Sour orange rootstock plants show genetic diversity (Lamine and Mliki, 2015) among them which may reflect in differences in relative tolerance to Phytophthora diseases. To find an alternative rootstock possessing all the qualities needed for $P$. nicotianae tolerance and successfully grow in the LRGV; four citrus rootstocks including sour orange rootstock were subjected to high concentrations of $P$. nicotianae inoculation.

\section{Materials and Methods}

Plant material. Four citrus rootstocks were screened for $P$. nicotianae tolerance including sour orange (Citrus aurantium), Bitters-C22 citrandarin (C. sunki $\times$ Swingle Poncirus trifoliata), and hybrids Sarawak pummelo $(C$. maxima $) \times \operatorname{Rio} \operatorname{Red}(C$. paradisi Macfadyen) grapefruit and Sarawak pummelo $(C$. maxima $) \times$ Bower mandarin $(C$. reticulata Blanco). This last hybrid was included because it is a similar cross that resulted sour orange even though it was bred as a scion. The Sarawak $\times$ Rio Red cross was originally performed for scion improvement. Grapefruit is a pummelo $\times$ sweet orange hybrid, whereas sweet orange is a pummelo $\times$ mandarin with $75 \%$ of the mandarin parent, so we decided to test Sarawak $\times$ Rio Red hybrid. Seeds were thoroughly washed with Golden-Glo soap (Spartan, Maumee, OH) and surface-sterilized with $10 \%$ commercial bleach $(5.25 \% \mathrm{NaOCl})$ for $20 \mathrm{~min}$ and rinsed three times with autoclaved reverse osmosis water.

Preparation of $P$. nicotianae stock and seed inoculation. Pure P. nicotianae culture, previously isolated from LRGV soil and citrus fibrous root and maintained in our laboratory, was used in this study (Chaudhary, 2018). Identity for this culture was previously confirmed by morphological and culture characteristics, and polymerase chain reaction (PCR). V-8 agar plugs with 7$\mathrm{d}$-old cultures were placed in $1 \mathrm{~L}$ of clarified V8 broth $(50 \mathrm{~mL} \mathrm{V8} \mathrm{juice,} 0.5 \mathrm{~g} \mathrm{CaCO} 3$, $949.5 \mathrm{~mL}$ of water), and incubated in the dark for $7 \mathrm{~d}$ at room temperature $\left(24{ }^{\circ} \mathrm{C}\right)$, after which the cultures were poured out into beakers topped with strainers to separate the agar plugs from V8 broth. Zoospores and chlamydospores were produced using standard methods that were previously described (Dhingra and Sinclair, 1995). The zoospore concentration was adjusted to $10^{6}$ zoospores/ $\mathrm{mL}$ to inoculate the seeds. The mycelium, zoospores, and chlamydospores were mixed with sterile Metro Mix soil (Sun Gro Horticulture, Agawam, MA) which was moistened to field capacity to produce soil with high concentrations of $P$. nicotianae inoculum (Colburn and Graham, 2007).

Inoculation of PGIS. A total of 408 seeds of each rootstock were inoculated. The seeds were placed in autoclaved paper towels moistened with autoclaved double distilled (DD) water and stored in a tightly closed tray. Pregermination was completed under laboratory conditions at room temperature until radicles emerged from most seeds. After 2 weeks, PGIS were placed into petri dishes $(150 \times 15 \mathrm{~mm})$ with $50 \mathrm{~mL}$ of zoospore suspension per dish and placed under light for $24 \mathrm{~h}$.

Inoculation of NPGIS. A total of 408 seeds of each rootstock were inoculated. NPGIS were immersed in a chlamydospore solution for $5 \mathrm{~min}$ and sown into Metro Mix soil infested with $P$. nicotianae as previously described. Two trays were designated for the planting of each rootstock treatmentNPGIS and PGIS - for a total of 16 trays, with 204 seeds per tray.

Afterward, NPGIS and PGIS trays were reinoculated with $P$. nicotianae by adding the suspension into the soil and moistened to field capacity. Plastic trays with no holes for drainage were chosen and metal-net linens were placed inside. The metal-net linens allowed drainage of excess water and root to grow through, thus facilitate visual identification of root rot and continuous inoculation of the germinated seeds. Roots were clipped to accelerate $P$. nicotianae continuous infection at two and four months after initial planting.

Plant evaluation. Eleven months postinoculation, the plants from each tray were removed and classified as dead or alive. Live plants were evaluated and rated on plant decay from a level of 1 to 3 (Fig. 1). Level 1 represented low decay, level 2 represented moderate decay, and level 3 represented high decay. Plants were characterized level 1 if the root system showed no signs of root decay, the stem remained green, and leaves did not exhibit yellowing. Plants characterized at level 2 had some thinning roots, partially yellow leaves, and slight browning on the stem. Plants characterized at level 3 had yellowing leaves, browning stem, and roots with extreme thinning. Plants were classified as dead or alive by uprooting each plant from each individual tray and analyzing its overall condition. Plants in each tray classified as alive were individually photographed and measured for plant height and root length. Plants classified as dead from each tray were recorded, but no further measurements were taken. To test for the presence and viability of $P$. nicotianae, root samples were taken from both the live and dead plants. Additionally, soil samples from each tray were collected in Ziploc bags to measure $P$. nicotianae propagule density. Once plants were classified, the remaining surviving plants were replanted in the same soil and left to grow for an additional 7 months after which dead plants were discarded and remaining plants were evaluated for root rot tolerance. The total postinoculation time was 18 months.

Detection of $P$. nicotianae in infected plants and soil. The propagule densities were measured using previously described methods (Bright et al., 2004; Timmer et al., 1988). Root samples were surface sterilized with $10 \%$ commercial bleach $(5.25 \% \mathrm{NaOCl})$ for 15 min, rinsed three times with DD water, and cut into $1-\mathrm{cm}$ pieces. Both root and soil samples were placed on CMA-PARPH medium plates (Jeffers, 2006) and analyzed for $P$. nicotianae propagule densities, expressed as colony forming units (cfu) per $\mathrm{cm}^{3}$ soil.

Conventional PCR assay. DNA was isolated from a small piece of mycelium using the Qiagen DNeasy Plant Mini Kit (Qiagen, Valencia, CA). To detect $P$. nicotianae, conventional PCR (cPCR) assay (Grote et al., 2002) was performed on $2 \mu \mathrm{L}$ of DNA in a $25-\mu \mathrm{L}$ reaction using the r-Gradient Thermoblock (Biometra GmbH, Göttingen, Germany). The PCR products were analyzed by electrophoresis on $1 \%$ agarose gels stained with ethidium bromide, in TAE buffer and visualized on a BioSpectrum Darkroom (U1traviolet Products, Upland, CA).

Statistical analysis. The test results given in Table 1 imply no statistically significant difference between the lengths of the live seedlings subject to NPGIS and PGIS treatments. As a result, in the further analysis, we combined the data for NPGIS and PGIS. To determine whether the rootstocks differ with respect to live or dead status and to determine if there is a difference among the rootstocks at the conditional levels 2 and 3, chi-square tests were performed. Level 1 was not included in the testing due to insufficient data. Post hoc tests for pairwise comparisons of proportions were carried out to determine which of the four rootstocks stood out among the others, having most different proportion of Live/Total counts after 11 months. All statistical analyses were performed using JMP 13.0.0 (2016), SAS Institute Inc. (Cary, $\mathrm{NC})$.

\section{Results}

Plant decay, height, and root length for each citrus rootstock. The plant height and root length measurements for the seedlings derived from NPGIS and PGIS seeds at 11month postinoculation with $P$. nicotianae are shown in Fig. 2 and Table 1. Plants were 


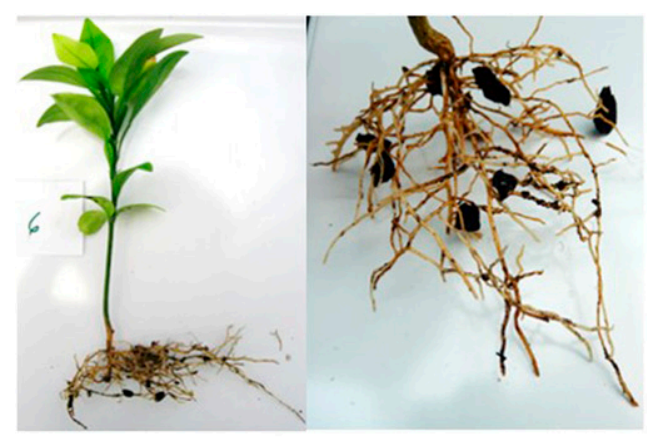

Level 1

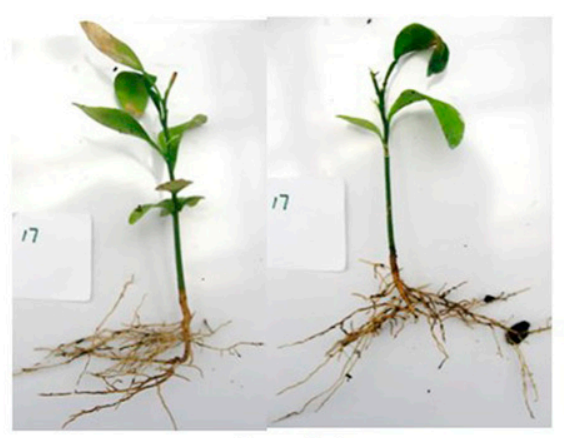

Level 2

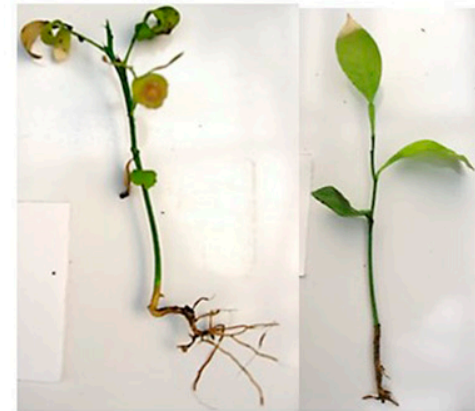

Level 3

Fig. 1. Citrus plant decay showed three levels of disease symptoms, levels 1, 2, and 3, at 11 months postinoculation with Phytophthora nicotianae.

Table 1. Plant height and root length (cm) from seedlings derived from non-pregerminated inoculated seeds (NPGIS) were compared with the seedlings derived from pregerminated inoculated seeds (PGIS) by rootstock to evaluate their performance at 11-months postinoculation with Phytophthora nicotianae.

\begin{tabular}{|c|c|c|c|c|c|c|c|c|c|c|c|c|}
\hline \multicolumn{7}{|c|}{ Shoot } & \multicolumn{6}{|c|}{ Root } \\
\hline & \multicolumn{2}{|c|}{ L1 } & \multicolumn{2}{|c|}{ L2 } & \multicolumn{2}{|c|}{ L3 } & \multicolumn{2}{|c|}{$\begin{array}{r}\text { L1 } \\
\end{array}$} & \multicolumn{2}{|c|}{ L2 } & \multicolumn{2}{|c|}{ L3 } \\
\hline Rootstock & NPGIS & PGIS & NPGIS & PGIS & NPGIS & PGIS & NPGIS & PGIS & NPGIS & PGIS & NPGIS & PGIS \\
\hline Sarawak $\times$ Bower & 12.5 & 11.2 & 11.5 & 11.6 & 7.9 & 8.9 & 14.1 & 11.1 & 11.4 & 11.1 & 7.81 & 12.8 \\
\hline$P$ value & & 0.39 & & 0.83 & & 0.51 & & 0.11 & & 0.77 & & $0.01 *$ \\
\hline Sour orange & - & 9.30 & 7.00 & 9.50 & 7.50 & 7.75 & - & 6.50 & 6.00 & 5.60 & 4.78 & 4.05 \\
\hline$P$ value & & & & 0.13 & & 0.69 & & & & 0.73 & & 0.38 \\
\hline Bitters-C22 & - & - & 12.00 & 10.30 & 9.59 & 8.90 & - & - & 5.00 & 7.50 & 5.77 & 5.90 \\
\hline$P$ value & & & & & & 0.43 & & & & & & 0.94 \\
\hline$\underline{\text { Sarawak } \times \text { Rio Red }}$ & - & 12.30 & 一 & 7.60 & 一 & 6.00 & 一 & 11.10 & 一 & 7.00 & 一 & 4.50 \\
\hline
\end{tabular}

L1, L2, and L3: levels 1, 2, and 3 of plant decay symptoms.

*Significantly different.

\section{Shoot Height}

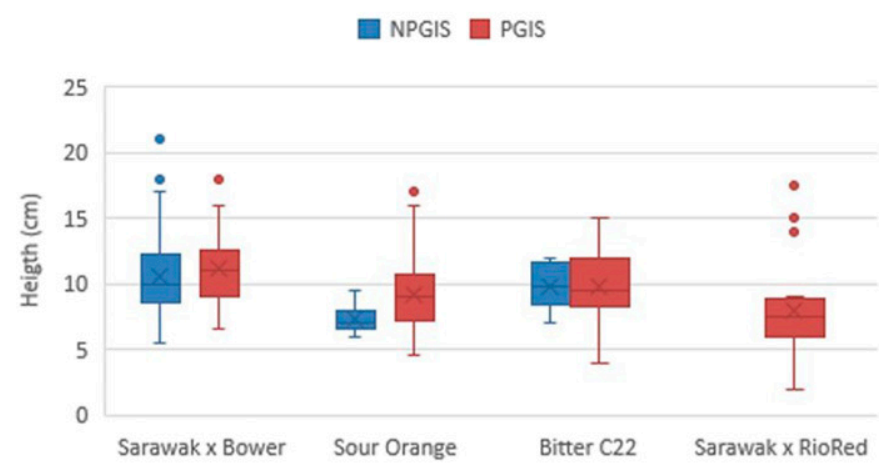

Root Length

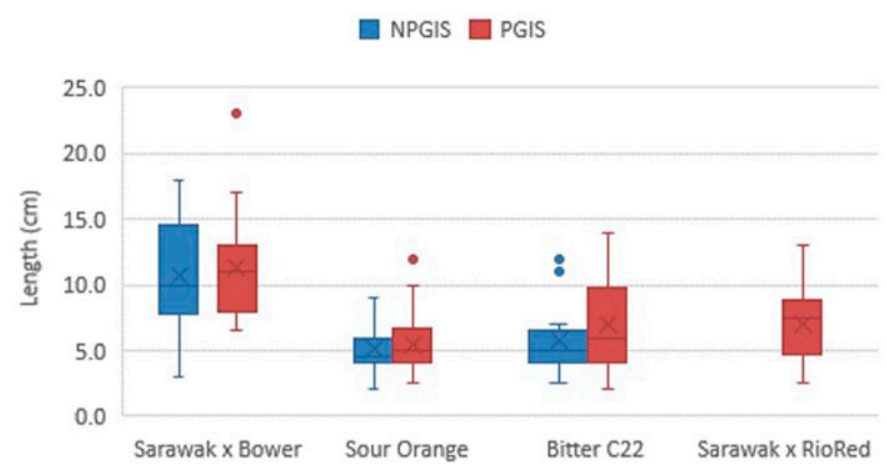

Fig. 2. The boxplots display the range in plant height and root length measurements for the seedlings derived from non-pregerminated (NPGIS) and pregerminated (PGIS) seeds at 11 months postinoculation with Phytophthora nicotianae. The dots represent outliers.

classified into levels based on visual cues of the root rot symptoms shown by each plant. An analysis was run for each rootstock between treatment groups and level classification to determine if there was a statistical difference $(P<0.05)$ between each level (Table 1).

Sour orange. There were no surviving sour orange NPGIS plants at 11 months postinoculation that could be classified as level 1; therefore, there was no analysis done between the NPGIS group and the four PGIS plants classified as level 1. Level 2 plant height for the PGIS treatment group averaged to $2.5 \mathrm{~cm}$ taller than the NPGIS group but still was not significantly different. The root measurements between NPGIS and PGIS for level 2 differed by less than $0.5 \mathrm{~cm}$. A level
3 category was designated for the most damaged plants and sour orange NPGIS group had nine plants collected while PGIS group had 10 plants. Level 3 NPGIS and PGIS displayed fairly equal overall plant height and root length with means differing less than $1 \mathrm{~cm}$ for both measurement averages. Analysis of variance (ANOVA) performed for the shoot length of the NPGIS did not provide significant results between levels $(P=0.782)$ nor did the shoot length analysis of the PGIS group $(P=0.157)$. The root length analysis for the NPGIS treatment group did not provide a significant difference $(P=0.705)$; however, the root length analysis for the PGIS treatment group did show statistical differences between classification levels $(P=$ 0.048). Only one PGIS sour orange plant survived 18 months postinoculation with $P$. nicotianae.

Sarawak pummelo $\times$ Bower mandarin. The Sarawak pummelo $\times$ Bower mandarin level 1 NPGIS treatment group $(\mathrm{n}=5)$ resulted in a plant height with a mean of $12.50 \mathrm{~cm}$, whereas the PGIS group had a slightly lower mean of $11.20 \mathrm{~cm}(\mathrm{n}=20)$ but did not provide a significant difference $(P=$ 0.39 ). The corresponding root measurements of level 1 Sarawak pummelo $\times$ Bower mandarin NPGIS and PGIS treatment groups also did not provide a significant difference in lengths $(P=0.11)$. Level 2 plant height and root length measurements of NPGIS and PGIS groups were almost identical, with means having a difference of less than 0.5 $\mathrm{cm}$, therefore did not have a significant 
Table 2. Contingency table: status by rootstock.

\begin{tabular}{lccccc}
\hline Count total \% & C22 & Sarawak $\times$ Bower & Sarawak $\times$ RioRed & Sour orange & Total \\
\hline Dead & 112 & 89 & 133 & 174 & 508 \\
& 15.36 & 12.21 & 18.24 & 23.87 & 69.68 \\
Live & 28 & 96 & 24 & 73 & 221 \\
& 3.84 & 13.17 & 3.29 & 10.01 & 30.32 \\
Total & 140 & 185 & 157 & 247 & 729 \\
& 19.20 & 25.38 & 21.54 & 33.88 & \\
Tests & & & & & $R^{2}(\mathrm{U})$ \\
N & & $\mathrm{df}$ & - LogLike & 0.0322 \\
729 & 3 & 32.014891 & & \\
& & & $\chi 2$ & $<>\chi^{2}$ \\
Likelihood ratio & & 64.030 & $<0.0001^{*}$ \\
Pearson & & 64.675 & $<0.0001^{*}$ \\
\hline
\end{tabular}

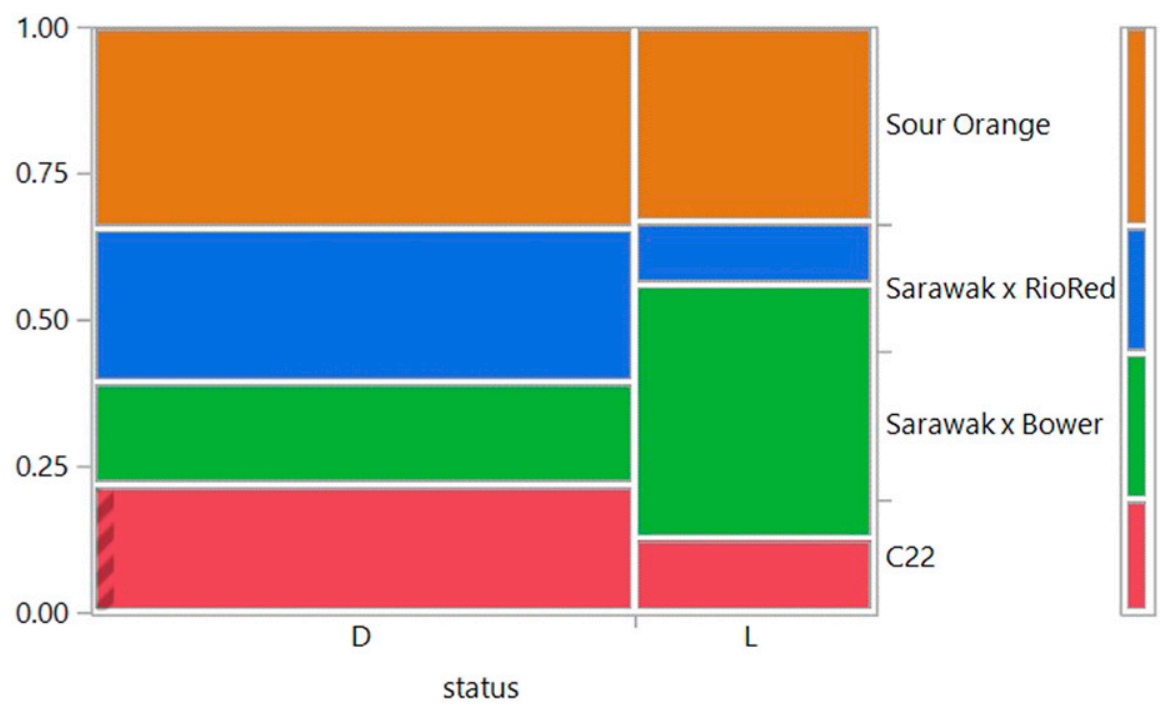

Fig. 3. Contingency analysis of rootstock by status (dead/live).

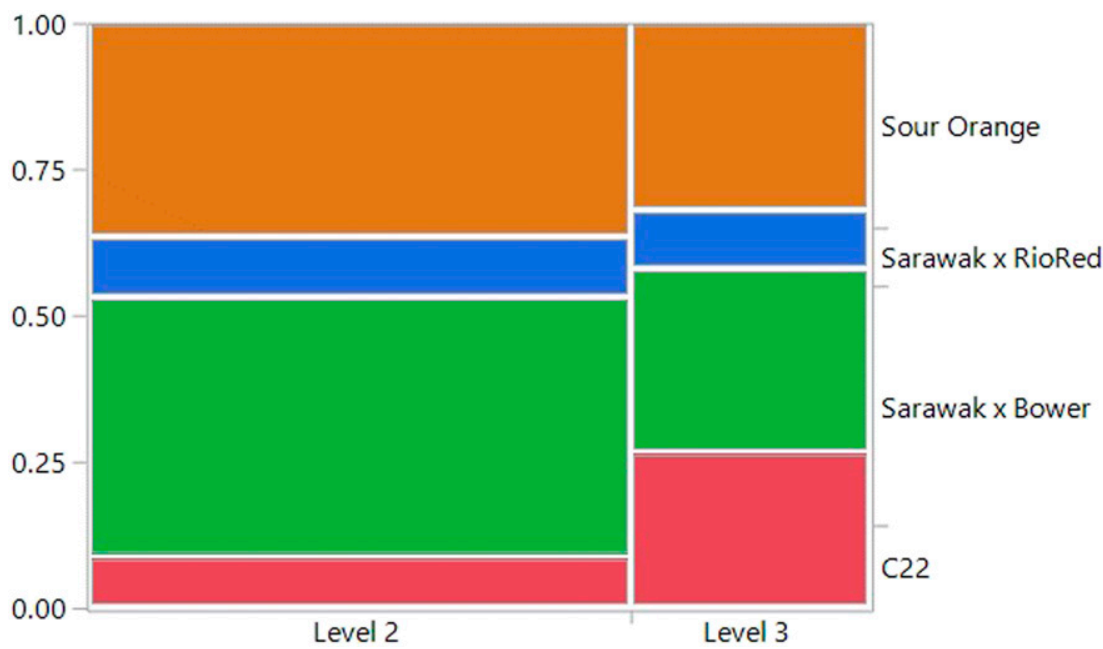

Fig. 4. Contingency analysis of rootstock by level of plant decay.

difference. Level 3 shoot heights for NPGIS and PGIS groups were not significantly different $(P=0.51)$, but the root lengths were significantly different with PGIS seeds growing $5 \mathrm{~cm}$ longer. An ANOVA performed between levels of the NPGIS group determined there was a significant difference for both shoot and root measurements, with $P$ values of 0.002 and $<0.001$, respectively. The pregerminated treatment group did not show significant differences between the PGIS group for either shoot length $(P=0.079)$ or root length $(P=0.584)$.

Bitters-C22 citrandarin. There were no seedlings that could be classified as level 1 for NPGIS and PGIS; therefore, no analysis was performed for this level. An analysis was not conducted between Level 2 NPGIS and PGIS treatment groups due to the large difference in sample sizes. One plant from the NPGIS treatment group displayed moderate symptoms enough to be classified at Level 2 with a height of $12 \mathrm{~cm}$ and root length of 5 $\mathrm{cm}$. PGIS had 11 plants that were classified as Level 2 with a mean shoot height of $10.3 \mathrm{~cm}$ and root length of $7.5 \mathrm{~cm}$. Plants classified at a Level 3 for this rootstock did not show a significant difference in average plant height or root length between NPGIS and PGIS treatment groups where in both cases the differences were less than one centimeter and $P$ values were 0.43 and 0.94 , respectively. The NPGIS treatment group had 11 plants collected for evaluation. There were no plants classified as level 1, one plant classified as level 2 and 11 plants classified as level 3. There were no significant differences calculated for either treatment group between any levels. A greater sample size would have provided a more accurate analysis to determine the statistical difference between classification levels.

Sarawak pummelo $\times$ RioRed grapefruit. There were no Sarawak pummelo $\times$ Rio Red grapefruit NPGIS group plants that survived at 11 months postinoculation collection. Because no measurements could be taken, comparison analyses were not performed between NPGIS and PGIS groups by level. The NPGIS group did not provide any surviving plants 11 months postinoculation. The PGIS treatment group did have 24 surviving plants in total, and there were significant differences between means for both the plant height $(P=$ $0.008)$ and root measurements $(P<0.001)$.

Confirmation of $P$. nicotianae in plants and soil. The presence of $P$. nicotianae was confirmed in each of the PARPH media plates by observing colony morphology, sporangium, hyphal, and oospore characteristics (Jeffers, 2006). The propagules in the infested soil where the plants were raised ranged from 424 to $1361 \mathrm{cfu} / \mathrm{cm}^{3}$ at 11 -month post inoculation. The soil sample taken from the tray where there was only one surviving sour orange rootstock plant at 18 -month post inoculation showed propagule count of 890 $\mathrm{cfu} / \mathrm{cm}^{3}$. The root pieces consistently produced characteristic $P$. nicotianae colonies on CMA-PARPH medium plates. An expected PCR amplification product of $737 \mathrm{bp}$ was obtained with all the DNA samples derived from all the morphologically characterized colonies.

Phytophthora tolerance in different citrus rootstocks. Plants collected from each individual tray displayed symptoms corresponding to $P$. nicotianae infection; leaves exhibited yellowing, roots were thinning, and stems were fragile and brown. A contingency table (Table 2) and a mosaic graph 
(Fig. 3) were developed for the four rootstocks by the status dead (D) or live (L). The $R^{2}$ test had a $P$ value of 0.0322 ; hence, the rootstocks differed in status D or L. Mosaic graph and contingency table for the four rootstocks by level 2 and level 3 for the category live are shown in Fig. 4 and Table 3, respectively. The $R^{2}$ test had a $P$ value 0.0216 . Therefore, given that the plants are alive, there is difference between the rootstocks at the conditional levels 2 and 3 . Pairwise comparisons of proportions for the four rootstocks indicated that the proportion of Sarawak $\times$ Bower is significantly different from the other three rootstocks. Indeed, the proportion of live for Sarawak $\times$ Bower $(96 /$ $185=0.52)$ is much higher than the proportions of the others. The results given in Table 4 identified the percent of live Sarawak $\times$ Bower seedlings as significantly higher than that for all other rootstocks.

Only surviving sour orange plant. After 18 months postinoculation, only one PGIS sour orange plant out of all treatments survived, and it did not display any symptoms corresponding to $P$. nicotianae infection. Leaves on the sour orange plant were not discolored, the stem was sturdy and visibly healthy (Fig. 5A), and the root system showed no signs of thinning or root decay (Fig. 5B).

\section{Discussion}

The economic losses due to Phytophthora diseases in the LRGV citrus orchards and unavailability of a resistant rootstock led to the screening of different citrus rootstocks for tolerance. Rootstocks such as Swingle citrumelo, Carrizo citrange, and Troyer citrange are tolerant to $P$. nicotianae-induced diseases; however, they are not adapted to the LRGV soils.

Rootstocks in the LRGV should be tolerant to $P$. nicotianae, high $\mathrm{pH}$ calcareous soils, and preferentially cold hardy. The most urgent need is tolerance/resistance to Phytophthora and adaptability to our soil conditions; we decided to start looking at potential variation in seedlings of rootstocks already tested in the LRGV and also at population of hybrids that we recently produced. One important characteristic of any citrus rootstock is that they should present a high degree of nucellar embryony to maintain uniformity of propagated scion varieties. Bitters-C22 citrandarin was screened due to its past performance exhibiting all favorable traits, including high degree of polyembryony. Bitters-C22 has shown tolerance to freezing temperatures as well as to calcareous soils, while still producing quality fruit (Federici et al., 2009). After a 6-year field trial in the LRGV, the Bitters-C22 rootstock produced the highest yield over six other rootstocks, which included sour orange (Louzada et al., 2008). The Bitters-C22 rootstock was susceptible to $P$. nicotianae infection, whereas trifoliate orange was described as resistant after field and greenhouse trials (Graham, 1995). Federici et al. (2009) described

Table 3. Contingency table: level by rootstock

\begin{tabular}{|c|c|c|c|c|c|}
\hline Count total \% & $\mathrm{C} 22$ & Sarawak $\times$ Bower & Sarawak $\times$ RioRed & Sour Orange & Total \\
\hline \multirow[t]{2}{*}{ Level 2} & 12 & 61 & 14 & 50 & 137 \\
\hline & 6.09 & 30.96 & 7.11 & 25.38 & 69.54 \\
\hline \multirow[t]{2}{*}{ Level 3} & 16 & 19 & 6 & 19 & 60 \\
\hline & 8.12 & 9.64 & 3.05 & 9.64 & 30.46 \\
\hline \multirow[t]{2}{*}{ Total } & & 80 & 20 & 69 & 197 \\
\hline & 14.21 & 40.61 & 10.15 & 35.03 & \\
\hline \multicolumn{6}{|l|}{ Tests } \\
\hline $\mathrm{N}$ & & $\mathrm{df}$ & \multicolumn{2}{|c|}{-LogLike } & $R^{2}(\mathrm{U})$ \\
\hline \multirow[t]{2}{*}{197} & & 3 & \multirow{2}{*}{\multicolumn{2}{|c|}{$\begin{array}{c}5.2920186 \\
\chi^{2}\end{array}$}} & 0.0216 \\
\hline & & & & & $P>\chi^{2}$ \\
\hline \multicolumn{2}{|c|}{ Likelihood ratio } & & \multicolumn{2}{|c|}{10.584} & $0.0142 *$ \\
\hline \multicolumn{2}{|c|}{ Pearson } & & \multicolumn{2}{|c|}{11.393} & $0.0098^{*}$ \\
\hline
\end{tabular}

Table 4. Pairwise comparisons of proportions using Holm-Bonferroni adjustment method.

\begin{tabular}{lccc}
\hline$P$ value & C22 & Sarawak $\times$ Bower & Sarawak $\times$ RioRed \\
\hline Sarawak $\times$ Bower & $<0.0001$ & & \\
Sarawak $\times$ RioRed & 0.3607 & $<0.0001$ & \\
Sour orange & 0.1057 & $<0.0001$ & 0.0048 \\
\hline
\end{tabular}

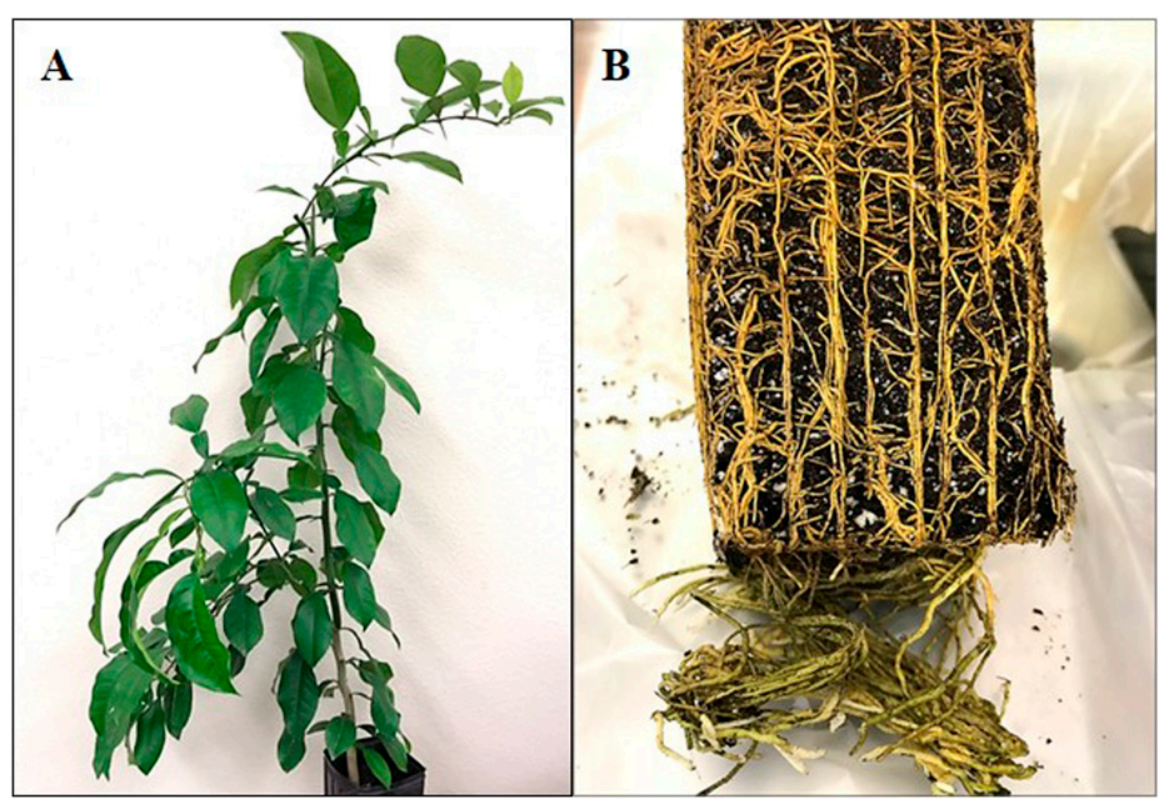

Fig. 5. The sour orange rootstock plant derived from pregerminated seeds was actively growing at 18 months postinoculation with Phytophthora nicotianae. It had a strong root system with no signs of thinning or root rot.

Bitters-C22 as moderately tolerant to $P$. nicotianae, and therefore in this study, Bitters-C22 was expected to perform well. However, after the evaluation of rootstocks 11 months postinoculation in this study, Bitters-C22 did not perform well, and only 28 of 816 plants survived. Even though the survival rate was low, the surviving plants did have among the highest plant height and equivalent root length compared with the other three rootstocks in this study.

Sour orange is believed to be a hybrid of $C$. reticulata (mandarin) and $C$. grandis (pummelo) according to nursery stock evaluations and molecular marker analyses (Barrett and Rhodes, 1976; Nicolosi et al., 2000). Because sour orange is believed to be a hybrid of these two species, similar qualities of sour orange hybrids could be achieved by crossing mandarins and pummelos (Grosser et al., 2004). Crosses between these two species have provided rootstocks with tolerance to $P$. nicotianae in greenhouse conditions as well as field conditions (Grosser et al., 2007). In this study, Sarawak pummelo $\times$ Bower mandarin rootstock hybrid showed the highest seed survival rate with 96 plants at 11 months postinoculation. Plants exhibited leaf drop, stem yellowing, and fibrous root rot at lower degrees than the other rootstocks in this study. The root length and plant height were the highest of all rootstocks measured and had only moderate root damage. However, 18 months 
postinoculation the tolerance of these plants was eventually overcome by $P$. nicotianae induced diseases. Pummelo does not present nucellar embryony, producing only monoembryonic zygotic seed; therefore, it should be expected that the many of its offspring would also be monoembryonic. However, there is still chance of obtaining hybrids that have some degree of polyembryony, such as sour orange, which is an offspring of the same kind of cross. If any of the tested hybrid shows high resistance to Phytophthora and is monoembryonic, propagation by tissue culture would be an option.

Grapefruit was described as susceptible (Hutchison and Grimm, 1972; Klotz, 1978) while pummelo was noted as resistant to $P$. nicotianae induced diseases (Ollitrault et al., 2006). Rio Red grapefruit provides highquality fruit with visually appealing red flesh color, and field observation in Texas show Rio Red to have some tolerance to Phytophthora (unpublished data). Hybrid seeds of these two rootstocks were selected for $P$. nicotianae tolerance screening with the objective of combining some fruit favorable traits and develop more tolerance to $P$. nicotianae. In this study, Sarawak pummelo $x$ Rio Red grapefruit seedlings showed the lowest survival rate of 24 plants total, which included both PGIS and NPGIS inoculated seed treatment groups. The NPGIS group did not have any surviving plants 11 months postinoculation. The surviving plants were on average the shortest plants recovered from the screening.

Sour orange was a candidate for screening against $P$. nicotianae diseases because it is the most commonly used rootstock in the LRGV. Seedlings variation in sour orange was first reported by Webber (1932) from experiments started in 1914 and conducted for more than 15 years. Xiang and Roose (1988) reported percentage of zygotic seeds greater than $30 \%$ in Taiwanica sour orange. Regardless of the percentage of zygotic seeds, sour orange has been the best ever rootstock for high $\mathrm{pH}$ calcareous soils and when high-quality scion production is desired. It seems that this does not cause enough variation to hinder this rootstock. Castle et al. (1993) described sour orange as tolerant to foot rot, cold temperatures, and capable of producing high-quality yields. Hutchison and Grimm (1972) had some success with sour orange clones and determined they were moderately resistant to $P$. nicotianae in Florida. However, when Graham (1995) tested the ability of root regeneration of sour orange, it was found to be intolerant to $P$. nicotianae infection. The difference in tolerance could be due to the amount of $P$. nicotianae inoculum present in the soil or the developmental stage of the seedlings. In this study, PGIS and NPGIS seeds were used for each rootstock, and both were exposed to high amounts of $P$. nicotianae inoculum. Eleven months postinoculation, sour orange had the second highest survival rating with more than 70 plants. Most plants did exhibit the typical $P$. nicotianae disease symptoms and had the shortest root length and plant height compared with the other rootstocks. However, after an additional 7 months in the same $P$. nicotianae infested soil, the sole surviving rootstock was sour orange and it was visibly healthy. Aboveground the leaves were uniformly green with no yellowing, and below ground there were no signs of fibrous root decay. The sour orange plant shown to be highly tolerant/resistant to infection by $P$. nicotianae. This plant has continued growing for more than 2 years in heavily infested soil while not showing any symptoms as of this writing. The sour orange plant was propagated by cuttings and will be evaluated under field conditions.

To investigate the origin of Phytophthora-resistant sour orange (PRSO) plant, simple sequence repeat (SSR) marker analysis (Barkley et al., 2006; Kijas et al., 1997) was conducted using this plant and six sour orange lines (T1, T2, and T3 are standard sour orange ID: VI 95 from UCR Citrus Clonal Protection Program, T25 = Brazilian sour orange, $\mathrm{T} 21=$ standard sour orange, and $\mathrm{T} 20=$ Regular sour orange) that are currently used for the propagation of sour orange rootstock in the Texas A\&M University-Kingsville Citrus Center. PRSO had two TAA1 alleles between 700 and 800 bp DNA size markers that are polymorphic among four parental lines except T20 and T2, both of which had the same two alleles (Supplemental Fig. 1). This may suggest that PRSO could be derived from a nucellar embryo of either of T20 and T2. However, the possibility of nucellar origin of PRSO from either of the lines were excluded because T20 and T2 had no or multiple CAGG9 alleles, whereas PRSO had single allele (Supplemental Fig. 1). Although SSR marker analysis failed to pinpoint two parental lines from which PRSO was originated, the data indicated that PRSO could be derived from a hybridization between T20 and T21 considering their physical proximity in the field.

\section{Conclusion}

In summary, among the four citrus rootstocks evaluated for Phytophthora tolerance, Sarawak $\times$ Bower hybrid has significantly performed well at 11 months postinoculation. A resistant sour orange plant was obtained that was the only plant to survive at 18 months postinoculation. This rootstock plant may offer a viable solution to Phytophthora-associated problems in citrus production under the Lower Rio Grande Valley area of South Texas.

\section{Literature Cited}

Barrett, H.C. and A.M. Rhodes. 1976. A numerical taxonomic study of affinity relationships in cultivated citrus and its close relatives. Syst. Bot. 1(2):105-136.

Barkley, N.A., M.L. Roose, R.R. Krueger, and C.T. Federici. 2006. Assessing genetic diversity and population structure in a citrus germplasm collection utilizing simple sequence repeat markers (SSRs). Theor. Appl. Genet. 112: 1519-1531.
Bowman, K.D., J.P. Albano, and J.D. Graham. 2002. Greenhouse testing of rootstocks for resistance to Phytophthora species in flatwoods soil. Proc. Fl. State Hort. Soc. 115:10-13.

Bowman, K.D., J.H. Graham, and R.C. Adair, Jr. 2003. Young tree growth in a flatwoods rootstock trial with Diaprepes weevil and Phytophthora diseases. Proc. Fl. State Hort. Soc. 116:249-251.

Bright, D.B., J.H. Graham, M.S. Irey, and L.E. Baucum. 2004. Soil, rootstock, and climatic factors affect populations of Phytophthora nicotianae in south Florida citrus plantings. Proc. Fl. State Hort. Soc. 117:148-151.

Cacciola, S.O. and G.M. di San Lio. 2008. Management of citrus diseases caused by Phytophthora spp., p. 61-84. In: A. Ciancio and K.G. Mukerji (eds.). Integrated management of diseases caused by fungi, phytoplasma and bacteria. Integrated Management of Plant Pests and Diseases, vol. 3. Springer, Dordrecht, the Netherlands.

Castle, W.S., D.P.H. Tucker, A.H. Krezdorn, and C.O. Youtsey. 1993. Rootstocks for Florida citrus (Univ. Florida Publ. SP-42), 2nd ed. 15 May 2020. <https://crec.ifas.ufl.edu/extension/ citrus_rootstock/Rootstock-Literature/Rootstocks $\% 20$ for $\% 20$ Florida $\% 20$ Citrus.pdf $>$.

Chaudhary, S. 2018. Incidence, distribution, and epidemiology of phytophthora diseases of citrus in south Texas and their interaction with Huanglongbing. Texas A\&M University, College Station, PhD diss. 15 May 2020. <http:// hdl.handle.net/1969.1/174478>

Colburn, G.C. and J.H. Graham. 2007. Protection of citrus rootstocks against Phytophthora spp. with a hypovirulent Isolate of Phytophthora nicotianae. Phytopathology 97:958-963.

Dhingra, O. and J.B. Sinclair. 1995. Basic plant pathology methods. 2nd ed. CRC Press, Boca Raton, FL.

Fang, J.G. and P.H. Tsao. 1995. Efficacy of Penicillium funiculosum as a biological agent against Phytophthora rots of azalea and citrus. Phytopathology 85:871-878.

Federici, C.T., R.S. Kupper, and M.L. Roose. 2009. 'Bitters', 'Carpenter' and 'Furr' trifoliate hybrids: Three new citrus rootstocks. 15 May 2020. $<$ http://plantbiology.ucr.edu/faculty/new \%20citrus\%20rootstocks\%202009.pdf>.

Graham, J.H. 1995. Root regeneration and tolerance of citrus rootstocks to root rot caused by Phytophthora nicotianae. Phytopathology 85 : 111-117.

Graham, J.H. and J.A. Menge. 1999. Root health: Fungal diseases, p. 126-135. In: L.W. Timmer and L.W. Duncan (eds.). Citrus health management. APS Press, St. Paul, MN.

Graham, J.H. 1990. Evaluation of tolerance of citrus rootstocks to Phytophthora root rot in chlamydospore-infested soil. Plant Dis. 74: 743-746.

Graham, J.H. and J.A. Menge. 2000. Phytophthorainduced diseases, p. 12-15. In: Compendium of citrus diseases. 2nd ed. APS Press, St. Paul, $\mathrm{MN}$.

Grosser, J.W., V.M. Urrutia, G. Ananthakrishnan, and P. Serrano. 2004. Building a replacement sour orange rootstock: Somatic hybridization of selected mandarin + pummelo combinations. J. Amer. Soc. Hort. Sci. 129:530-534.

Grosser, J.W., J.H. Graham, A. Hoyte, H.M. Rubio, D.B. Bright, J. Gmitter, C.X. Chen, and F.G. Gmitter, Jr. 2007. Continued development of rootstocks tolerant of the Diaprepes/Phytophthora complex via greenhouse screening. Proc. Annu. Meet. Fla. State Hort. Soc. 120:103-109. 
Graham, J. and E. Feichtenberger. 2015. Citrus Phytophthora diseases: Management challenges and successes. J. Citrus Pathol. 2:1-11.

Grote, D., A. Olmos, A. Kofoet, J.J. Tuset, E. Bertolini, and M. Cambra. 2002. Specific and sensitive detection of Phytophthora nicotianae by simple and nested-PCR. Eur. J. Plant Pathol. 108:197-207.

Hung, P.M., P. Wattanachai, S. Kasem, and S. Poeaim. 2015. Efficacy of Chaetomium species as biological control agents against Phytophthora nicotianae root rot in Citrus. Mycobiology 43:288-296.

Hutchison, D.J. and G.R. Grimm. 1972. Variation in Phytophthora resistance of Florida rough lemon and sour orange clones. Proc. Annu. Meet. Fla. State Hort. Soc. 85:38-39.

Jeffers, S.N. 2006. Identifying species of Phytophthora. Department of Entomology, Clemson University, Clemson, SC. 15 May 2020. <https:// www.fs.fed.us/foresthealth/fhm/sp/sod/misc/culturing_species_phytophthora.pdf $>$.

Kijas, J.M.H., M.R. Thomas, J.C.S. Fowler, and M.L. Roose. 1997. Integration of trinucleotide microsatellites into a linkage map of citrus. Theor. Appl. Genet. 94:701-706.

Klotz, L.J. 1978. Fungal, bacterial and nonparasitic diseases and injuries originating in the seedbed, nursery and orchard, p. 1-66. In: The citrus industry: Vol. 4. Crop protection. W. Reuther, E.C. Calavan, and G.F. Carman (eds.). University of California Agricultural Sciences Publications, Richmond, CA.
Kunta, M., J.V. da Graça, and M. Skaria. 2007. Molecular detection and prevalence of citrus viroids in Texas. HortScience 42:600-604.

Lamour, K.H., M.L. Daughtrey, D.M. Benson, J. Hwangand, and M.K. Hausbeck. 2003. Etiology of Phytophthora drechsleri and $P$. nicotianae (= P. parasitica) diseases affecting floriculture crops. Plant Dis. 87:854-858.

Lamine, M. and A. Mliki. 2015. Elucidating genetic diversity among sour orange rootstocks: A comparative study of the efficiency of RAPD and SSR markers. Appl. Biochem. Biotechnol. 175:2996-3013.

Louzada, E.S., H.S. del Rio, M. Sétamou, J.W. Watson, and D.M. Swietlik. 2008. Evaluation of citrus rootstocks for the high $\mathrm{pH}$, calcareous soils of South Texas. Euphytica 164:13-18.

Ludowici, V.A., W. Zhang, L.M. Blackman, and A.R. Hardham. 2013. Phytophthora nicotianae, p. 113-123. In: K. Lamour (ed.). Phytophthoraa global perspective. $\mathrm{CAB}$ International, Wallingford, Oxfordshire, UK.

Meng, Y., Q. Zhang, W. Ding, and W. Shan. 2014. Phytophthora parasitica: A model oomycete plant pathogen. Mycology 5:43-51.

Naqvi, S.A.M.H. 2004. Diagnosis and management of certain important fungal diseases of citrus, p. 247-290. In: S.A.M.H. Naqvi (ed.). Diseases of fruits and vegetables: Vol. I. Diagnosis and management. Kluwer Academic, Dordrecht, the Netherlands.

Nicolosi, E., Z.N. Deng, A. Gentile, S. La Malfa, G. Continella, and E. Tribulato. 2000. Citrus phy- logeny and genetic origin of important species as investigated by molecular markers. Theor. Appl. Genet. 100:1155-1166.

Ollitrault, P., Y. Froelicher, D. Dambier, F. Luro, and M. Yamamoto. 2006. Seedlessness and ploidy manipulations. In: I.A. Khan (ed.). Citrus genetics, breeding and biotechnology. CABI, Wallingford, UK; Cambridge, MA.

Savita, G.S. and A. Nagpal. 2012. Citrus diseases caused by Phytophthora species. GERF Bull Biosci. 3:18-27.

Tashiro, N., S. Uematsu, and Y. Ide. 2012. First report of Phytophthora palmivora as a causal pathogen of citrus brown rot in Japan. J. Gen. Plant Pathol. 78:233-236.

Timmer, L.W., H.A. Sandler, J.H. Graham, and S.E. Zitko. 1988. Sampling citrus orchards in Florida to estimate populations of Phytophthora parasitica. Phytopathology 78:940-944.

Timmer, L.W., J.H. Graham, and S.E. Zitko. 1998. Metalaxyl-resistant isolates of Phytophthora nicotianae: Occurrence, sensitivity, and competitive parasitic ability on citrus. Plant Dis. 82:254-261.

Webber, H.J. 1932. Variation in citrus seedlings and their relation to rootstock selection. Hilgardia 7:1-77.

Xiang, C. and M.L. Roose. 1988. Frequency and characteristics of nucellar and zygotic seedlings of rootstocks. Scientia Hort. 37:47-59.

Zitko, S.E. and L.W. Timmer. 1994. Competitive parasitic abilities of Phytophthora parasitica and $P$. palmivora on fibrous roots of citrus. Phytopathology 84:1000-1004. 


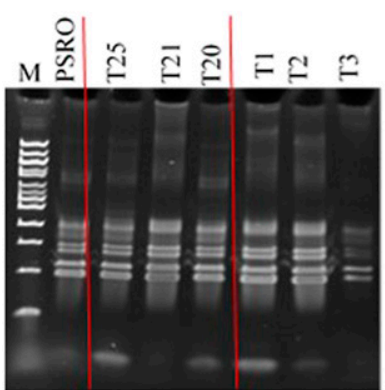

TAA27

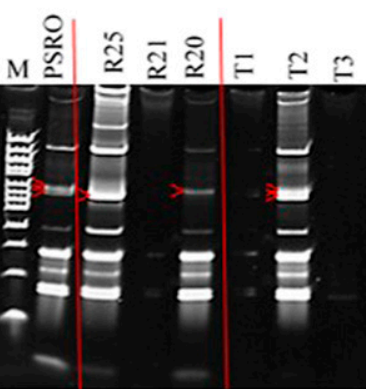

TAA1

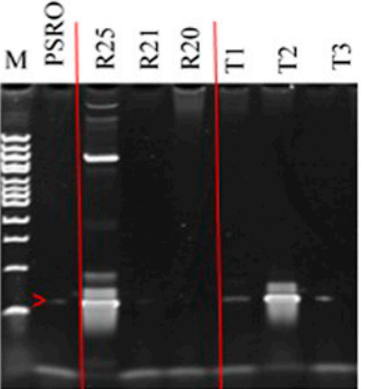

CAGG9

Supplemental Fig. 1. Comparison of simple sequence repeat (SSR) marker profiles between Phytophthoraresistant sour orange (PSRO) and sour orange parental lines. Marker loci are indicated on the bottom. $>$ indicated polymorphic markers. T1, T2, and T3 are standard sour orange ID: VI 95 from UCR Citrus Clonal Protection Program, T25 = Brazilian sour orange, T21 = standard sour orange, and T20 = Regular sour orange. 